\title{
Xanthomas: Clinical and pathophysiological relations
}

\author{
Ales Zak\#, Miroslav Zeman, Adolf Slaby, Marek Vecka\#
}

\begin{abstract}
Background. Xanthomas are well circumscribed lesions in the connective tissue of the skin, tendons or fasciae that predominantly consist of foam cells; these specific cells are formed from macrophages as a result of an excessive uptake of low density lipoprotein (LDL) particles and their oxidative modification.

Results. Until recently, xanthelasma was considered to be only a cosmetic lesion; however, according to the results of recent prospective studies it is connected with an increased cardiovascular risk and reduced average lifespan. Pathogenetic mechanisms involved in the development of xanthomas resemble early stages of atherogenesis. In clinical practice, xanthomas can signalise various congenital or acquired dyslipidemias. The most prevalent form of xanthomas is xanthelasma palpebrarum. Tendinous and tuberous xanthomas are typical for autosomal dominant hypercholesterolemia, as well as for some rare conditions, such as cerebrotendinous xanthomatosis and familial $\beta$-sitosterolemia. In patients with familial hypercholesterolemia, the presence of tendinous xanthomas has been shown to be associated with a two to four times higher risk for cardiovascular disease. Eruptive xanthomas are skin manifestations of a severe hypertriglyceridemia and implicate an elevated risk for acute pancreatitis or type 2 diabetes mellitus. Xanthoma striatum palmare is pathognomic for primary dysbetalipoproteinemia, whereas diffuse plane xanthomas are frequently associated with paraproteinemia and lymphoproliferative disorders.

Conclusion. Thorough familiarity with the clinical presentation of xanthomas helps in the diagnosis and follow-up of different forms of dyslipidemia. Moreover, xanthelasma palpebrarum, the most prevalent form of xanthomas, is connected with increased risk of atherothrombotic disease independently of conventional cardiovascular risk factors. To fully understand the pathogenesis, further experimental and clinical research is required.
\end{abstract}

Key words: xanthoma, dyslipidemia, oxidatively modified low density lipoproteins, foam cells, inflammation, cardiovascular risk

Received: November 13, 2013; Accepted: March 28, 2014; Available online: April 29, 2014

http://dx.doi.org/10.5507/bp.2014.016

$4^{\text {th }}$ Department of Internal Medicine, $1^{\text {st }}$ Faculty of Medicine, Charles University in Prague and General Faculty Hospital in Prague, Czech Republic

"The authors contributed equally to the work

Corresponding author: Ales Zak, e-mail:azak@vfn.cz

\section{INTRODUCTION}

Xanthomas evolve as clusters of foam cells in the connective tissue of the skin, tendons and fasciae and occasionally in the periosteum. Foam cells are formed from macrophages as a consequence of gradual intracellular accumulation of lipids taken up by specific receptors or by the mechanism of phagocytosis ${ }^{1}$. The clinical picture of xanthomas is variable, from soft to semisolid skin macules or papules to large nodules, usually of a yellow colour $($ Greek $x a n t h o s=$ yellow), due to the presence of carotene contained in lipids ${ }^{2}$.

In recent years, interest in xanthomas has been stimulated for several reasons. The mechanisms involved in the development of these pathological lesions appear to be analogous to those participating in early stages of atherosclerotic plaques. From the clinical point of view, xanthomas are often associated with inborn or acquired dyslipidemias and can be pathognomic for some of them. Of inborn errors of lipid metabolism, autosomal dominant hypercholesterolemias are relatively common. This broad group consists of familial hypercholesterolemia caused by mutations in the genes encoding the LDLreceptor $(L D L R)$, familial defective apolipoprotein $\mathrm{B}-100$ with mutations in the gene $A P O B$, and non-FH/non-FDB hypercholesterolemia with mutations in the gene PCSK9. Other types of xanthomas are helpful diagnostic markers of severe hypertriglyceridemia ${ }^{3}$ and primary dysbetalipoproteinemia ${ }^{4}$. Xanthomas can also call attention to the presence of some uncommon conditions, such as cerebrotendinous xanthomatosis caused by mutations in the sterol 27-hydroxylase gene (CYP27A) which induce a 27-hydroxylase deficiency, and familial $\beta$-sitosterolemia (phytosterolemia) with mutations in the genes encoding the specific sterol transporters $A B C G 5$ and $A B C G 8$ $\left(\right.$ ref. $\left.^{5,6}\right)$. The development of xanthomas can signalise an elevated risk for serious metabolic and cardiovascular diseases, as well as for lymphoproliferative malignancies. The aim of this article is to give an overview of some recent research studies concerning xanthomas, mainly from the clinical point of view.

\section{PATHOGENETIC MECHANISMS}

The development of xanthomas starts by an increased local extravasation of lipids through the vascular wall to the interstitial space of connective tissues. Monocytes 
and macrophages that have accumulated there take up lipid particles by specific receptors or by means of phagocytosis of LDL aggregates and lipid complexes with antibodies: In this way, foam cells can be formed. From the formal pathological viewpoint, the following factors take part: 1) high local concentrations of lipids in the connective tissue, 2) the presence of qualitatively different lipoproteins at normal plasma lipid concentrations, 3 ) increased extravasation of lipids (increased vascular permeability, increased local circulation, chronic inflammation), 4) lipid synthesis in situ and their deposition in histiocytes, 5) dysfunction of the reverse cholesterol transport ${ }^{4,7}$.

Native lipids (lipoproteins) do not induce foam cell formation. Intracellular LDL catabolism by LDL-receptors (apoB/E receptors) goes on slowly and cholesterol homeostasis is effectively regulated. Free cholesterol, released from LDL after its internalisation, inhibits its de novo synthesis. Moreover, free cholesterol inhibits synthesis of LDL-receptors and thus suppresses LDL endocytosis by cells. On the other hand, chemically, mainly oxidatively modified LDL particles are taken up by macrophages much more rapidly. Macrophages express scavenger receptors that mediate binding and uptake of ox-LDL. As a result of the modified structure, their affinity to LDL-receptors is low and they mostly bind to scavenger receptors [SR-A, SR-B1, CD36, lectin-like oxidized LDL (ox-LDL) receptor-1 (LOX-1)]. Cholesterol caught by scavenger receptors does not activate the feed-back regulation of de novo synthesis. When cholesterol uptake exceeds the capacity of cholesterol efflux, cholesterol accumulation results in droplet formation. The cholesterol efflux is mediated by the reverse cholesterol transport ${ }^{8,9}$.

In the course of gradual lipid oxidation, minimally modified LDL (mm-LDL) is formed with chemical changes limited to the lipid component (conjugated di-

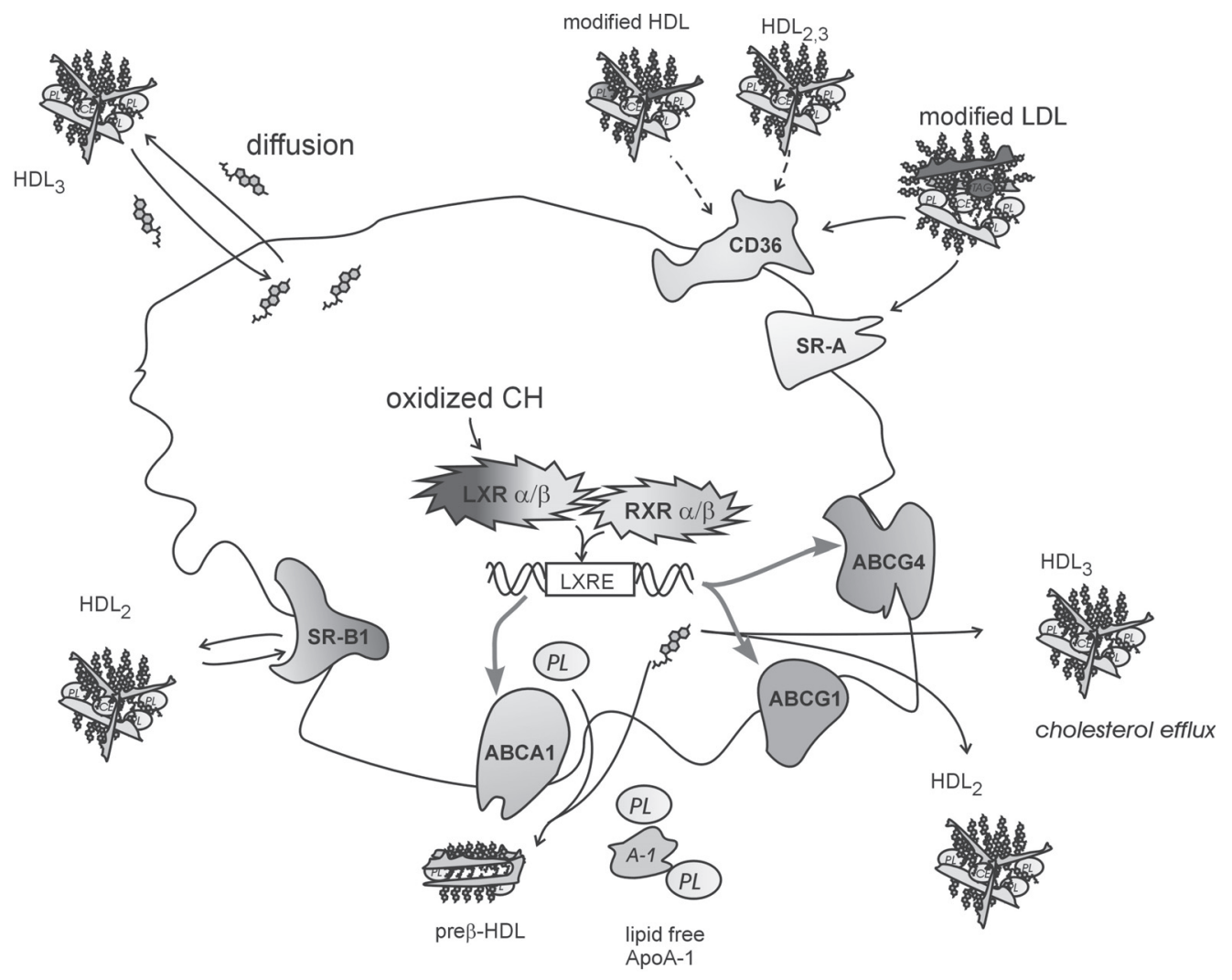

cholesterol efflux

Fig. 1. The reverse cholesterol transport.

High concentration of cholesterol $(\mathrm{CH})$ in macrophage (Ma) leads to its transformation into a foam cell. Homeostasis and equilibration of $\mathrm{CH}$ in $\mathrm{Ma}$ is ensured by several mechanisms facilitating externalisation (efflux) of $\mathrm{CH}$ from the cell through specific translocators or simple diffusion: (i) $\mathrm{CH}$ can be externalised by passive diffusion (governed by concentration gradient) to spherical $\mathrm{HDL}_{3}$ particles; (ii) using $\mathrm{ABCA} 1, \mathrm{CH}$ is actively transported with phospholipids (PL) onto the complexes of PL and apoA1, giving rise to discoidal HDL (dHDL) particles; (iii) $\mathrm{CH}$ is actively transported through transporters $\mathrm{ABCG} 1$ and $\mathrm{ABCG} 4$ which bind to $\mathrm{HDL}_{3}$ particles thus forming $\mathrm{HDL}_{2}$; $\mathrm{SR} \mathrm{B} 1$ receptors enable the transfer of cholesterol (with the help of concentration gradient) to the surface of spherical particles $\mathrm{HDL}_{2}$ and $\mathrm{HDL}_{3}$. Free (nonesterified) cholesterol is esterified with LCAT. The $\mathrm{HDL}_{2}$ particles are selectively depleted of cholesteryl esters after binding to liver SR B1 receptors. Expression of ABCA1, ABCG1, ABCG4 transporters is regulated by cellular concentration of oxysterols. These molecules are ligands for the liver $\mathrm{X}$ receptors (LXR) and after the heterodimerization with retinoic acid receptors (RXR), the oxysterol-LXR-RXR complex collocalizes with specific binding sites within the sequences of promotors of genes responsible for the expression of respective transporters. 
Table 1. Xanthomas in various types of dyslipidemias.

\begin{tabular}{lllll}
\hline Gnoseologic unit & Molecular defect & Heritability & Prevalence & Type of xanthoma \\
\hline FH & LDLR & $\mathrm{AD}$ & $1: 500(\mathrm{ht}) ; 1: 10^{6}(\mathrm{hm})$ & xanthoma tendineum, \\
FDB & APOB & $\mathrm{AD}$ & $1: 800(\mathrm{ht}) ; 1: 4 \times 10^{6}(\mathrm{hm})$ & xanthoma tuberosum \\
FH3 & PCSK $9^{7}$ & $\mathrm{AD}$ & $1: 25 \times 10^{3}(\mathrm{ht})$ & xanthelasma/ arcus lipoides corneae \\
$\beta$-sitosterolemia & ABCG5/ABCG8 & $\mathrm{AR}$ & $1: 5 \times 10^{6}$ & xanthoma tendineum \\
CTX & CYP27A & $\mathrm{AR}$ & $1: 5 \times 10^{4}$ & xanthoma tuberosum \\
Type III HLP & E2/E2 & $\mathrm{AR}$ & $1: 5 \times 10^{3}$ & xanthoma striatum palmare \\
& & & & eruptive (tuberoeruptive) xanthomas \\
Familiar & LPL & $\mathrm{AR}$ & $1: 10^{6}$ & xanthoma eruptivum \\
hyperchylomicronemia & APOC-II & $\mathrm{AR}$ & & \\
Familiar HTG & $?$ & $\mathrm{AD}$ & rare & xanthelasma palpebrarum \\
Severe HTG & $?$ & $\mathrm{AD}$ & $18: 10^{5}$ & xanthoma eruptivum \\
PHC $^{5}$ & $?$ & Polygenic & $1: 100-150$ & xanthelasma palpebrarum \\
FCH $^{6}$ & $?$ & $\mathrm{AD}$, polygenic & $1: 100$ & arcus lipoides corneae \\
\hline
\end{tabular}

FH - familial hypercholesterolemia; FDB - familial defect of apolipoprotein B-100; FH3 - non-FH/non-FDB hypercholesterolemia;

Type III HLP - hyperlipoproteinemia type III (primary/familiar dys- $\beta$-lipoproteinemia); CTX - cerebrotendinous xanthomatosis; severe HTG - severe hypertriglyceridemia; PHC - polygenic hypercholesterolemia; LDLR - gene for LDL-receptor; $A P O B$ - gene for apolipoprotein B-100; PCSK9 - gene for proprotein convertase subtilisin/kexin 9; LPL - gene for lipoprotein lipase; $A P O C-I I$ - gene for apolipoprotein C-II; AD - autosomal dominant; AR - autosomal recessive; hm - homozygous; ht - heterozygous; DLP - dyslipoproteinemia; FCH - familiar combined hyperlipidemia.

Explanations and remarks:

1) the presence of xanthelasma palpebrarum and arcus lipoides corneae is important for diagnosis of familial autosomal dominant hypercholesterolemias (FH, FDP, FH3) only in individuals under 20 years;

2) when relapse of the disease and worsening of dyslipidemia;

3) type III HLP - needs combination of homozygocy for apoE2/E2 (with autosomal recessive heritability) and other hyperlipidemia-forming factor (familiar DLP) or the presence of secondary DLP (decompensated DM, hypothyreosis, obesity, alcohol intake, pharmacologic dosage of estrogens).

4) onset of severe HTG (type V HLP with high VLDL and presence of chylomicrons)

5) PHC is caused by combination of exogenous and genetic factors (mutations/polymorphisms in apoE4, CETP, hepatic lipase, LPL, PCSK9, $A B C G 5 / G 8, L C A T, C Y P 7 A 1)$;

6) $\mathrm{FCH}$ - it is supposed that the polymorphisms of apoB-100, LPL, apoE, cluster of apoC-III/apoA-I/apoA-IV take part in the pathophysiology of the disease; the defects/polymorphisms of apoC-II and receptor for acylation stimulating protein $(A S P)$ are also possible.

7) FH3 - some patients have mutations in the PCSK9 gene encoding neural apoptosis regulated convertase 2 (NARC-1) which enhances the degradation of LDL-receptors. The mutations connected with upregulation of PCSK9 (gain of function) are linked to hypercholesterolemia.

enes, aldehydes). These particles induce synthesis of the monocyte colony-stimulating factor (M-CSF) and promote differentiation of macrophages. After binding to glycosaminoglycans, oxidation of LDL particles continues, affecting both lipid and apolipoprotein components and giving rise to oxidised LDL (ox-LDL) characterised by strong proinflammatory effects. Many factors have been shown to take part in lipid oxidation, including metal ions $\left(\mathrm{Cu}^{2+}, \mathrm{Fe}^{2+}\right)$ and various enzymes (myeloperoxidase, lipoxygenase, NADPH oxidase) liberated from macrophages, fibroblasts and endothelial cells ${ }^{8}$.

Reverse cholesterol transport (RCT) is a dynamic process resulting in removal of superfluous cholesterol from peripheral tissues. It comprises several pathways and consecutive steps given schematically in Fig. 1. 1) cholesterol transfer from the intracellular space of macrophages to the cell membrane, 2) cholesterol externalisation (efflux) through specific transporters (ABCA1, ABCG1, ABCG4, SR-B1) or by simple diffusion, 3) esterification of free cholesterol by lecithin: cholesterol acyltransferase (LCAT), formation of spherical HDL particles, 4) transfer of cholesterol esters from HDL to apoB lipoproteins (VLDL, IDL, LDL) by cholesterylester transfer protein (CETP), 5) trapping of lipid particles by specific recep- tors in the liver (SR-B1 for HDL, LRP for IDL, betaVLDL and large HDL, LDL-R for IDL and LDL). The rate determining step is the transfer of cholesterol from cell membranes to HDL. While mutations in the gene for ABCA1 are rare, the efficacy of the reverse cholesterol transport is decreased in subjects with low plasma concentrations of HDL cholesterol due to the lack of cholesterol acceptors. As acceptor for the portion of cholesterol provided by ABCA1 serves the HDL fraction referred to as prebeta-HDL (lipid-free apolipoprotein A1), while $\mathrm{HDL}_{3}$ particles accept cellular cholesterol that passed by diffusion or was transported by ABCG1 and ABCG4. An alternative of reverse cholesterol transport consists in a selective exchange between peripheral tissues and organs with a high demand for cholesterol ${ }^{10,11}$.

Moreover, the transport of lipid particles from the intracellular space to the blood stream depends on the functional integrity of the lymphatic circulation. Recent studies challenge the older view that macromolecules can passively enter the blind ends of lymphatic capillaries. A specially regulated uptake mechanism for transcytosis of HDL was demonstrated in lymphatic endothelial cells expressing scavenger receptors SR-B1 (ref. ${ }^{12}$ ). Hypercholesterolemia is associated with impaired lym- 
phatic drainage and increased lipid accumulation in peripheral tissues ${ }^{13}$.

The relationship between oxidatively modified lipoproteins, reverse cholesterol transport and the development of xanthomas is supported by the results of clinical studies. In patients with familial hypercholesterolemia, the size of Achilles tendon xanthomas correlated positively with the titre of antibodies against oxidised LDL, negatively with the plasma concentration of $\mathrm{HDL}_{3}\left(\right.$ ref. $\left.^{14}\right)$. The incidence of tendon xanthomas in patients with familial hypercholesterolemia was significantly associated with age, sex, plasma concentration of LDL cholesterol and arterial hypertension ${ }^{15}$. Disorders of reverse cholesterol transport and low plasma concentrations of $\mathrm{HDL}_{3}$ have been described even in normolipidemic subjects with Achilles tendon xanthomas ${ }^{16}$. In LDL particles incubated with xanthoma tissues, a considerable increase in malondialdehyde was proven (up to 15 times) simultaneously with a significant increase in the electrophoretic mobility of LDL ( ref. $^{17}$ ). Oxidative modification of native LDL that takes place in the lysosomes of macrophages is accelerated by ferritin, slowed down by high values of $\mathrm{pH}$ and some fat-soluble antioxidants ${ }^{18}$. In this context, it can be hypothesised that proton pump inhibitors may decrease the formation of xanthomas and the possibility of atherosclerotic lesions by increasing lysosomal $\mathrm{pH}$ and consequently by inhibiting lysosomal $\mathrm{H}^{+} / \mathrm{K}^{+}$ATPase $^{19}$.

In a group of patients with genetically diagnosed familial hypercholesterolemia, carriers of tendon xanthomas had significantly higher plasma concentrations of TNF, IL-6, IL-8 and higher activities of tryptase than those without xanthomas. Incubation of macrophages with oxidatively modified LDL particles induced higher inflammatory responses in the carriers of xanthomas. Genetic predisposition of macrophages to high inflammatory responses consequently takes part in the pathogenesis of xanthomas. Free tryptase (released from mast cells, possessing $44 \%$ homology with the serine protease) can degrade $\mathrm{HDL}_{3}$ particles and decrease the efficiency of reverse cholesterol transport ${ }^{20}$.

\section{CLASSIFICATION AND CLINICAL PICTURE OF XANTHOMAS}

Xanthomas can be classified from several points of view. Detailed pathoanatomical as well as clinical schemes have been expounded with special attention to the requirements of dermatology and/or internal medicine (lipidology, haematology). For the purpose of a general review, the following groups seem useful: normolipidemic xanthomas (NX), hyperlipidaemic xanthomas (HX), and necrobiotic xanthogranuloma (NXG) (ref. ${ }^{21,22}$ ). Normolipidemic xanthomas mostly appear as diffuse flat skin lesions, while hyperlipidaemic types are polymorphous, often tuberous, and can affect either skin or tendons and joints. Xanthomas of both groups contain lipids (unesterified cholesterol, cholesteryl esters, and phospholipids) and collagen; histological examination reveals numerous foam cells.
Necrobiotic xanthogranuloma manifests itself as multiple skin deposits with tendency to ulcerations; histology shows Touton giant cells and necrotic foci ${ }^{2}$. Normolipidemic xanthomas and necrobiotic xanthogranuloma can be associated with monoclonal gammopathies and lymphoproliferative disorders ${ }^{22}$.

For clinical purposes, two groups have been proposed: I. papulonodular xanthomas: xanthoma eruptivum, tuberosum, tendineum and articulare, II. plane xanthomas: xanthoma diffusum planum, intertriginosum, striatum palmare, disseminatum and xanthelasma palpebrarum ${ }^{23}$. Common metabolic diseases associated with xanthomas are listed in Table 1.

\section{Xanthoma eruptivum}

Eruptive xanthoma is marked by a sudden eruption of yellowish skin papules 1-4 mm in diameter, encircled by an erythematous halo. Sites of predilection are buttocks, posterior thighs and elbows, as well as lumbar region. Eruptive xanthomas are causally associated with severe hypertriglyceridemia (TG $>11.2 \mathrm{mmol} / \mathrm{L}$ ) and can signalise the chylomicronemic syndrome. The eruption usually appears within three weeks after the increase in plasma triglycerides.

\section{Xanthoma tuberosum}

Tuberous xanthomas are flat or elevated yellowish nodules located in the dermis and subcutaneous tissue, from 3 millimetres to several centimetres in size. They mostly manifest themselves in the skin over joints (elbows, knees, joints of hands and feet), or on the buttocks. Tuberous xanthomas can occur in patients with autosomal dominant hypercholesterolemia, familial dysbetalipoproteinemia, $\beta$-sitosterolemia, or cerebrotendinous xanthomatosis, rarely in cases of secondary dyslipoproteinemias, e.g. nephrotic syndrome or hypothyreosis ${ }^{6,24,25}$.

\section{Xanthoma tendineum}

Tendinous xanthomas can diffusely infiltrate tendons, tendon attachments, ligaments, fascia and periosteum. They form free movable hard nodules or spindles covered by normal skin. Predilection sites are Achilles tendons, tendons on the backs of the hands and fingers, as well as elbows, knees and heels. Frequently, they evolve subperiosteally in the tuberositas tibiae (patellar tendon attachment). Thickening of the Achilles tendon can be recognised and quantified by imaging techniques even before the growth of a tubercle. Tendineous xanthomas evolve in connection with the same types of dyslipidemia as tuberous xanthomas appear, except for familial dysbetalipoproteinemia.

\section{Xanthoma diffusum planum}

Diffuse plane xanthomas form yellow to orange bands or plates in the dermis, usually affecting the skin of axillae, neck, shoulders or buttocks. This is a rare type of xanthoma, usually not connected with dyslipidemia. Its finding can warn of the presence of monoclonal gammopathy or lymphoproliferative disorders ${ }^{26}$. 


\section{Xanthoma striatum palmare}

Plane yellow to orange oblong structures in palmar flection lines (xanthoma striatum palmare) or yellowish colouring (hue) of the flection lines (xanthochromia striata palmaris). This type of xanthoma is almost pathognomic for primary dysbetalipoproteinemia. Sometimes it can be found in patients with newly diagnosed diabetes mellitus, hypothyreosis, or primary biliary cirrhosis ${ }^{27}$. Patients with chronic cholestasis can also have various xanthomas on the neck and multiple xanthelasmas of the eyelids. All these efflorescences can disappear after restoration of patency of the biliary duct or after the development of hepatic failure ${ }^{28}$.

\section{Xanthoma disseminatum}

A benign chronic cutaneous condition, that ranks among rare histiocytosis syndromes, preferentially affects males in childhood and adolescence. It is characterised by small orange-yellow, brown-red or blue-violet papules and nodules in the face (periorbitally, periorally) and intertriginous areas. Xanthoma disseminatum can also have extra-cutaneous manifestations, especially in the central nervous system, hypophysis or the respiratory airways ${ }^{2}$.

\section{Xanthelasma palpebrarum}

The most common type of cutaneous xanthoma presents itself as small yellowish, flat or minimally elevated plaques $($ Greek elasma $=$ plate $)$, soft or semisolid, located in the upper (in 70\%) or lower eyelids. Infrequently it can spread in both lids and form circular skin lesions ${ }^{29}$. In children and young adolescents, xanthelasma may signalise the presence of autosomal dominant hypercholesterolemia, together with arcus lipoides corneae, tuberous and tendinous xanthomas. Xanthelasma most commonly occurs in subjects over fifty years of age. About half of them have dyslipidemia (high LDL-C and TG, low HDL-C and apo A-1). The presence of xanthelasma palpebrarum should never be underestimated in clinical practice.

\section{Xanthogranuloma necrobioticum}

Necrobiotic xanthogranuloma is a rare progressive granulomatous disorder which manifests as multiple orange-yellow, brownish-red or blue-violet plaques and nodules. Predilection sites are periorbital regions but the condition can manifest anywhere on the head, neck and trunk; extra-cutaneous involvement is also known. Necrobiotic xanthogranuloma is usually associated with normolipidemia and can signalise monoclonal gammopathy or lymphoproliferative malignancies ${ }^{2,21}$.

\section{PREVALENCE OF XANTHOMAS}

Exact epidemiological data on the prevalence of various types of xanthoma are lacking and textbooks in clinical lipidology give differing data ${ }^{4,7}$. However the vast majority of cases (>95\%) are xanthelasma palpebrarum ${ }^{30}$. According to earlier studies, the prevalence was $0.3-1.1 \%$, in women twice as high as in men and subjects older than 50 years prevailed. A recent prospective study found a
$4.4 \%$ prevalence of xanthelasma in the population with an even distribution between men and women ${ }^{31}$. Similar data were obtained from our out-patient lipid clinic ${ }^{32}$. Xanthelasma palpebrarum was found in $10 \%$ of patients with isolated hypertriglyceridemia ${ }^{33}$. In some pregnant women, xanthelasma evolves during the first trimester of pregnancy and after delivery mostly disappears ${ }^{4}$.

Tendon xanthomas can be found in about 30\% familial hypercholesterolemic patients with proven mutations in the $L D L R$ gene. The prevalence increases from $7 \%$ in the third decennium to $40 \%$ in the sixth decennium ${ }^{15}$. Similar prevalence data (20-50\%) are given by other authors for clinically diagnosed patients with familial hypercholesterolemia. Abnormal texture and thickening of Achilles tendons were demonstrated in $68 \%$ of subjects with familial hypercholesterolemia ${ }^{34}$.

Eruptive xanthomas are pathognomic skin manifestations of severe hypertriglyceridemia (TG > $11.2 \mathrm{mmol} / \mathrm{L}$ ), a serious metabolic disorder with an estimated prevalence of 18 cases in 100000 inhabitants $^{35}$. Eruptive xanthoma was retrospectively documented in $10 \%$ of patients with severe hypertriglyceridemia ${ }^{36}$. According to older monographs, eruptive xanthomas can be found in up to $60 \%$ of patients with familial chylomicronemia ${ }^{33}$; this disorder is very rare ( $1: 1$ million live births). In a group of patients with severe hypertriglyceridemia (characterized by TG > $20 \mathrm{mmol} / \mathrm{L}$ ), 8.5\% exhibited eruptive xanthomas and $3 \%$ typical forms of xanthoma striatum palmare ${ }^{36}$.

\section{PROGNOSTIC SIGNIFICANCE OF XANTHOMAS}

Xanthelasma of the eyelids (xanthelasma palpebrarum), the most common type of xanthomas, has been until recently considered a benign cosmetic lesion ${ }^{31}$. Prospective studies have however shown that its presence (unlike that of arcus senilis corneae alone) was significantly associated with a shorter life span, on average by 15 years $^{37}$. Individuals with xanthelasma have dyslipidemia age-dependently in 20-70\% (ref. ${ }^{30}$ ). In a Danish prospective study (The Copenhagen City Heart Study) comprising almost 13000 subjects followed up for more than 20 years, the presence of xanthelasma was associated with a significantly increased risk of myocardial infarction (by 48\%), ischemic heart disease (by 38\%), and ischemic disease of the lower extremities (by 70\%), even after adjustment for some covariates, such as age, sex, diabetes mellitus, smoking, hypolipidemic treatment, and postmenopausal status ${ }^{31}$. Another study confirmed a significant association of xanthelasma with the prevalence of non-alcoholic fatty liver disease, recently assumed to be independent risk factor for ischemic heart disease ${ }^{38}$ and with increased intima-media thickness ${ }^{39}$.

Tendinous and tuberous xanthomas can signalise familial hypercholesterolemia and consequently the cardiovascular risk associated with elevated plasma concentrations of LDL cholesterol. According to a meta-analysis of 22 studies on patients with genetic diagnosis of familial hypercholesterolemia, the presence of tendon xanthomas was associated with a 3.2 times higher risk of cardiovascu- 
lar disease ${ }^{40}$. Similarly, the risk for premature cardiovascular disease was higher in genetically diagnosed patients with familial hypercholesterolemia and tendineous xanthomas, 2.3 times in men and 4.5 times in women, independently of the type of mutations in the $L D L R$ gene $^{15}$.

Tendinous and tuberous xanthomas can also be found in some rare metabolic disorders; elevated plasma concentrations of cholestanol (in cerebrotendinous xanthomatosis) or phytosterols (in familial $\beta$-sitosterolemia) bring about the deposition of these substances in connective tissues. Tendinous xanthomas can cause pain, especially if localised in the Achilles tendon (achillodynia). Occasionally, they can elicit a spontaneous rupture of the tendon ${ }^{14}$.

Eruptive xanthomas call attention to severe hypertriglyceridemia, especially in patients with newly diagnosed or decompensated diabetes mellitus; an elevated risk of acute pancreatitis occurs within the framework of the chylomicronemic syndrome ${ }^{35,36,41}$.

Diffuse plane xanthomas can be associated with paraproteinemia (multiple myeloma, monoclonal gammopathy of undetermined significance) and with lymphoproliferative diseases (skin lymphomas, chronic lymphatic leukaemia, chronic myeloid leukaemia ${ }^{22,26}$.

\section{DIAGNOSIS AND DIFFERENTIAL DIAGNOSIS}

The diagnosis of xanthomas is usually quite easy and based on the clinical picture. In unclear cases, skin biopsy for histopathological examination is indicated. Xanthomas associated with dyslipidemia and early atherosclerosis (xanthelasma, tendinous and tuberous xanthomas) require additional investigation. Personal and family histories can discover metabolic disorders and/or cardiovascular diseases, as well as the time of manifestation in the patient and his/her first degree relatives. The finding of xanthelasma should prompt a careful non-invasive examination of blood vessels (ultrasonography of arteries of the head and neck, intima-media thickness in the carotid arteries, ankle-brachial index) and sonography of the liver (to confirm or reject the presence of non-alcoholic fatty liver disease).

If familial hypercholesterolemia is suspected, the examination should be completed by imaging of the Achilles tendon (ultrasonography, computed tomography, magnetic resonance imaging). The method of first choice is ultrasonography (US) performed $2 \mathrm{cms}$ above the insertion into the calcaneum. US imaging is the less expensive nonradiating cross-sectional imaging method and depicts focal lesions that others fail to detect ${ }^{42}$. For familial hypercholesterolemia, increased thickness of the tendon (threshold values for age and sex are tabulated) is typical as well as loss of regular fibrous texture and the presence of echolucent areas. Moreover, these findings can differentiate between familial hypercholesterolemia and other types of primary dyslipidemias, e.g. polygenic hypercholesterolemia, familial combined dyslipidemia ${ }^{34,42}$.

For diagnosis of familial hypercholesterolemia, the following issues are to be considered: family history, clinical history of premature CHD, arcus senilis corneae, very high LDL cholesterol (typically above the $75^{\text {th }}$ percentile of the healthy population) on repeated measurements, and/or a causative mutation detected by molecular genetics, e.g. $L D L R, A P O B, P C S K 9$ (proprotein convertase subtilisinkexin subtype 9) mutations ${ }^{43}$. Secondary causes of hyperlipidaemia must be excluded by determining that liver enzymes, renal function, and thyroid hormones are normal and that there is no hyperglycaemia or albuminuria.

To identify asymptomatic coronary atherosclerosis, exercise electrocardiography, echocardiography, coronary artery calcification scanning with the Electron Beam CT (EBCT) and CT angiography are recommended. Some guidelines underscore the value of noninvasive imaging of atherosclerosis in assessing and managing asymptomatic FH subjects ${ }^{44}$.

The rare familial $\beta$-sitosterolemia manifests in childhood. Its clinical picture includes tendinous or tuberous xanthomas, premature atherosclerosis, and attacks of haemolysis, arthralgia or arthritis ${ }^{45}$. Cerebrotendinous xanthogranulomatosis is also rare (frequency 1: 50000 live births); the signs and symptoms in infancy and early childhood are cholestasis, cataract and diarrhoea; in adults, paraparesis, ataxia, dysarthria, decreased cognitive functions and dementia can complete the clinical picture. The examination should be completed with genetic tests ${ }^{6,25}$.

Plane diffuse xanthoma and necrobiotic xanthogranuloma require laboratory tests aimed at the presence of monoclonal gammopathy and lymphoproliferative disorders, including PET/CT, flow cytometry and histological examination of lymphatic nodes.

Dermatological and internal (incl. lipidologic) examination has to be performed in all patients with xathomas. If indicated, specialists in other branches of medicine are consulted (cardiology, angiology, ophthalmology, immunology, rheumatology).

If possible, genetic testing should be done (mutations in $L D L R$ and $A P O B$ genes, apoE isoforms, CYP27). In the case of suspected $\beta$-sitosterolemia, phytosterols are determined quantitatively by gas chromatography, possibly together with mass spectroscopy; plasma concentrations of $\beta$-sitosterol can be ten to sixty times higher and those of campesterol and stigmasterol three to six times higher than in normal subjects. The diagnosis can be confirmed by molecular genetic examination of $A B C G 5 / A B C G 8$ transporters (ref. ${ }^{5,45}$ ). Laboratory examination in patients with cerebrotendinous xanthogranulomatosis shows increased plasma concentrations of cholestanol (about six times) and high urinary excretion of bile alcohols.

\section{PREVENTION AND TREATMENT}

Prevention of xanthomas goes hand in hand with the management of the underlying disorders of lipid metabolism. Individuals with serious lipid disorders are indicated (according to the EBM principles) for statins as the firstchoice therapy. Combined drug therapy, i.e. statin plus ezetimibe and/or bile acid resin is recommended in patients with severe hypercholesterolemia. In patients with 
severe hypertriglyceridemia use of fibrates or niacin will reduce risk for acute pancreatitis. High intakes of omega-3 fatty acids are an alternative for treatment of severe hypertriglyceridemia ${ }^{46}$.

Hypolipidemic treatment can induce substantial regression of eruptive, palmar and tuberous xanthomas, while decreasing plasma levels of atherogenic lipoproteins toward normal. In the early phase of tendinous xanthomas, regression can be expected after twelve months of the treatment ${ }^{3,42,47}$. Massive xanthomas of the Achilles tendon can require surgical reconstruction ${ }^{48}$. Treatment of cerebrotendinous xanthomatosis consists in administration of chenodeoxycholic acid and statins ${ }^{6}$. Patients with $\beta$-sitosterolemia require dietary measures (restriction of phytosterols in food) and treatment with bile acid sequestrants (colestipol, cholestyramine) or cholesterol absorption inhibitors (ezetimibe). In the local treatment of disturbing forms of xanthelasma palpebrarum, laser ablation proved successful, as well as chemical ablation with trichloracetic acid ${ }^{49}$; surgical therapy is rarely indicated ${ }^{50}$.

\section{CONCLUSION}

Xanthomas are cutaneous conditions often associated with disorders of the lipid metabolism. Their evolution resembles early atherogenesis and consequently has been the object of intense biomedical research. From the clinical point of view, xanthomas cannot be considered as mere cosmetic lesions; they can signalise serious dyslipidemias, both common and rare, as well as an increased risk of metabolic, cardiovascular, and tumorous diseases. The present experience with the prevention and treatment of xanthomas has to be expanded and shared internationally.

\section{ACKNOWLEDGEMENTS}

This work was supported by Ministry of Health, Czech Republic - conceptual development of research organization RVO VFN64165 and Research project of Charles University in Prague, 1st Faculty of Medicine PRVOUK-P25/LF1/2.

\section{AUTHORSHIP CONTRIBUTIONS}

AZ: Conception and literature search; AZ, MZ, AS, MV: Manuscript writing; MV: Figures and tables.

\section{CONFLICT OF INTEREST STATEMENT}

None declared.

\section{REFERENCES}

1. Koumar V, Abbas AK, Fausto N, Aster JC, editors. Robbins and Cotran Pathologic Basis of Disease. 8th ed. Philadelphia: Saunders Elsevier; 2010.

2. Török L. Dermatological manifestations in internal diseases (in Czech). Heidelberg - Leipzig - Praha: J.A. Barth Verlag a ČLS J. E. Purkyně; 1998.

3. Renner R, Teuwen I, Harth W, Treudler R, Simon JC. Eruptive xanthomas with hypertriglyceridemia. Hautarzt 2008;59(12):995-9.

4. Durrington $P$, Sniderman A, editors. Hyperlipidaemia. Oxford: Health Press; 2000.

5. Alam M, Garzon MC, Salen G, Starc TJ. Tuberous xanthomas in sitosterolemia. Pediatr Dermatol 2000;17(6):447-9.

6. Kalidas K, Behrouz R. Inherited metabolic disorders and cerebral infarction. Expert Rev Neurother 2008;8(11):1731-41.

7. Thompson GR, editor. A Handbook of Hyperlipidemia. London: Current Science; 1990.

8. Miller Yl, Tsimikas S. Lipoprotein oxidation and modification. High-density lipoprotein metabolism. In: Ballantyne CM, editor. Clinical Lipidology. A Companion to Braunwald's Heart Disease. Philadelphia: Saunders Elsevier; 2009, p. 93-110.

9. Xu S, Ogura S, Chen J, Little PJ, Mos J, Liu P. LOX-1 in atherosclerosis: biological functions and pharmacological modifiers. Cell Mol Life Sci 2013;70(16):2859-72.

10. Brewer HB. High-density lipoprotein metabolism. In: Ballantyne CM, editor. Clinical Lipidology. A Companion to Braunwald's Heart Disease. Philadelphia: Saunders Elsevier; 2009, p. 45-55.

11. Toth PP. High-density lipoprotein. In: MH Davidson, PP Toth, KC Maki (eds.) Therapeutic Lipidology. Totowa, NJ, Humana Press 2007, 15999.

12. Lim HY, Thiam CH, Yeo KP, Bisoendial R, Hii CS, McGrath KC, Tan KW, Heather A, Alexander JS, Angeli V. Lymphatic vessels are essential for the removal of cholesterol from peripheral tissues by SR-BImediated transport of HDL. Cell Metab 2013;17(6):671-84.

13. Martel C, Li W, Fulp B, Platt AM, Gautier EL, Westerterp M, Bittman R, Tall AR, Chen SH, Thomas MJ, Kreisel D, Swartz MA, Sorci-Thomas MG, Randolph GJ. Lymphatic vasculature mediates macrophage reverse cholesterol transport in mice. J Clin Invest 2013;123(4):1571-9.

14. Tsouli SG, Kiortsis DN, Argyropoulou MI, Mikhailidis DP, Elisaf MS Pathogenesis, detection and treatment of Achilles tendon xanthomas. Eur J Clin Invest 2005;35(4):236-44.

15. Civeira F, Castillo S, Alonso R, Meriño-lbarra E, Cenarro A, Artied M, Martín-Fuentes P, Ros E, Pocoví M, Mata P, Spanish Familial Hypercholesterolemia Group. Tendon xanthomas in familial hypercholesterolemia are associated with cardiovascular risk independently of the low-density lipoprotein receptor gene mutation. Arterioscler Thromb Vasc Biol 2005;25(9):1960-5.

16. Matsuura F, Hirano K, Koseki M, Ohama T, Matsuyama A, Tsujii K, Komuro R, Nishida M, Sakai N, Hiraoka H, Nakamura T, Yamashita S. Familial massive tendon xanthomatosis with decreased highdensity lipoprotein-mediated cholesterol efflux. Metabolism 2005;54(8):1095-101.

17. Hirata Y, Okawa K, Ikeda M, Seike M, Matsumoto M, Kodama H. Low density lipoprotein oxidized in xanthoma tissue induces the formation and infiltration of foam cells. J Dermatol Sci 2002;30(3):248-55.

18. Wen Y, Leake DS. Low density lipoprotein undergoes oxidation within lysosomes in cells. Circ Res 2007;100(9):1337-43.

19. Namazi MR, Sharifian M. The potential anti-xanthoma and anti-atherosclerotic effects of proton pump inhibitors. J Clin Pharm Ther 2008;33(6):579-80.

20. Artieda M, Cenarro A, Junquera C, Lasierra P, Martínez-Lorenzo MJ, Pocoví M, Civeira F. Tendon xanthomas in familial hypercholesterolemia are associated with differential inflammatory response of macrophages to oxidized LDL. FEBS Lett 2005;579(20):4503-12.

21. Jeziorska M, Hassan A, Mackness MI, Woolley DE, Tullo AB, Lucas GS, Durrington PN. Clinical, biochemical, and immunohistochemical features of necrobiotic xanthogranulomatosis. J Clin Pathol 2003;56(1):64-8.

22. Szalat R, Arnulf B, Karlin L, Rybojad M, Asli B, Malphettes M, Galicier L, Vignon-Pennamen MD, Harel S, Cordoliani F, Fuzibet JG, Oksenhendler E, Clauvel JP, Brouet JC, Fermand JP. Pathogenesis 
and treatment of xanthomatosis associated with monoclonal gammopathy. Blood 2011;118(14):3777-84.

23. Štork J. Cutaneous conditions in disorders of metabolism and nutrition (in Czech). In: Štork J, Arenberger P, Pizinger K, Semrádová V, Vosmík F, editors. Dermatovenerologie. Praha: Galén - Karolinum; 2008, p. 259-274.

24. Singh RK, Simalti AK. Tuberous xanthoma. Indian Pediatr 2009;46(8):727.

25. Clayton PT. Disorders of bile acid synthesis. J Inherit Metab Dis 2011;34(3):593-604.

26. Spanou Z, Borradori L. Diffuse plane xanthomas, a cutaneous marker for monoclonal gammopathies and lymphoproliferative diseases. Eur J Haematol 2010;86(1):91.

27. Nagarajan DV, Boreham PA, Parfitt VJ. Palmar striated xanthomas. Postgrad Med J 2003;79(938):690.

28. Žák A, Zeman M. Secondary dyslipoproteinemias (in Czech). In: Svačina Š, editor. Disorders of metabolism and nutrition. Praha: Galén; 2010, p. 271-288.

29. Kim J, Kim YJ, Lim H, Lee SI. Bilateral circular xanthelasma palpebrarum. Arch Plast Surg 2012;39(4):435-7.

30. Bergman R. Xanthelasma palpebrarum and risk of atherosclerosis. Int J Dermatol 1998;37(5):343-5.

31. Christoffersen $M$, Frikke-Schmidt $R$, Schnohr $P$, Jensen $G B$, Nordestgaard BG, Tybjærg-Hansen A. Xanthelasmata, arcus corneae, and ischaemic vascular disease and death in general population: prospective cohort study. Brit Med J 2011;343:d5497. doi:10.1136/ bmj.d5497

32. Zeman M, Žák A, Herdová J. An analysis of plasma lipids and clinical characteristics of patients with xanthelasma palpebrarum (in Czech). Čas Lék čes 1981;120(26):806-8.

33. Šobra J. Inherited disorders of the lipid metabolism (in Czech). In: Hyánek J, editor. Clinical and biochemical aspects of inherited metabolic disorders. Praha: Avicenum; 1980, p. 200-240.

34. Junyent $M$, Gilabert R, Zambón D, Núñez I, Vela M, Civeira F, Pocoví M Ros $E$. The use of Achilles tendon sonography to distinguish familial hypercholesterolemia from other genetic dyslipidemias. Arterioscler Thromb Vasc Biol 2005;25(10):2203-8.

35. Leaf DA. Chylomicronemia and the chylomicronemia syndrome: a practical approach to management. Am J Med 2008;121(1):10-2.

36. Sandhu S, Al-Sarraf A, Taraboanta C, Frohlich J, Francis GA. Incidence of pancreatitis, secondary causes, and treatment of patients referred to specialty lipid clinic with severe hypertriglyceridemia: a retrospective cohort study. Lipids Health Dis 2011;10:157. doi: 10.1186/1476511X-10-157

37. Menotti A, Puddu PE, Lanti M, Maiani G, Fidanza F. Cardiovascular risk factors predict survival in middle-aged men during 50 years. Eur J Intern Med 2013;24(1):67-74.

38. Targher G, Byrne CD. Nonalcoholic fatty liver disease: A novel cardiometabolic risk factor for type 2 diabetes and its complications. $J$ Clin Endocrinol Metab 2013;98(2):483-95.

39. Pandhi D, Gupta P, Singal A, Tondon A, Sharma S, Madhu SV. Xanthelasma palpebrarum: a marker of premature atheroscle- rosis (risk of atherosclerosis in xanthelasma). Postgrad Med J 2012;88(1038):198-204.

40. Oosterveer DM, Versmissen J, Yazdanpanah M, Hamza TH, Sijbrands EJ. Differences in characteristics and risk of cardiovascular disease in familial hypercholesterolemia patients with and without tendon xanthomas: a systematic review and metaanalysis. Atherosclerosis 2009;207(2):311-7.

41. Richter WO. Chylomicronemia and chylomicronemia syndrome. In: Gotto AM, Mancini M, Richter WO, Schwandt P, editors. Treatment of Severe Dyslipoproteinemia in the Prevention of Coronary Heart Disease 3, Basel: Karger; 1992, p. 165-173.

42. Tsouli SG, Xydis V, Argyropoulou MI, Tselepis AD, Elisaf M, Kiortsis DN. Regression of Achilles tendon thickness after statin treatment in patients with familial hypercholesterolemia: an ultrasonographic study. Atherosclerosis 2009;205(1):151-5.

43. Civeira F. Guidelines for the diagnosis and management of heterozygous familial hypercholesterolemia. Atherosclerosis 2004;173(1):5568.

44. Nordestgaard BG, Chapman MJ, Humphries SE, Ginsberg HN, Masana L, Descamps OS, Wiklund O, Hegele RA, Raal FJ, Defesche JC, Wiegman A, Santos RD, Watts GF, Parhofer KG, Hovingh GK, Kovanen PT, Boileau C, Averna M, Borén J, Bruckert E, Catapano AL, Kuivenhoven JA, Pajukanta P, Ray K, Stalenhoef AFH, Stroes E, Taskinen M-G, Tybjærg-Hansen A. Familial hypercholesterolaemia is underdiagnosed and undertreated in the general population: guidance for clinicians to prevent coronary heart disease: Consensus Statement of the European Atherosclerosis Society. European Heart Journal 2013;34(5):3478-90.

45. Cheng WF, Yuen YP, Chow CB, Au KM, Chan YW, Tam SC. Sitosterolaemia and xanthomatosis in a child. Hong Kong Med J 2003;9(3):206-9.

46. Expert Panel on Dyslipidemia, Grundy SM, Arai H, Bartere P, Bersot TP, Betteridge DJ, Carmena R, Cuevas A, Davidson MH, Genest J, Kesäniemi YA, Sadikot S, Santos RD, Susekov A, Sy R, Tokgozoglu L, Watts GF, Zhao D. An International Atherosclerosis Society Position Paper: Global recommendations for the management of dyslipidemia: Executive summary. Atherosclerosis 2014; 232(2):410-3.

47. Park JR, Jung TS, Jung JH, Lee GW, Kim MA, Park KJ, Kim DR, Chang $\mathrm{SH}$, Chung SI, Hahm JR. A case of hypothyroidism and type 2 diabetes associated with type $\mathrm{V}$ hyperlipoproteinemia and eruptive xanthomas. J Korean Med Sci 2005;20(3):502-5.

48. Moroney PJ, Besse JL. Resection of bilateral massive Achilles tendon xanthomata with reconstruction using a flexor hallucis longus tendon transfer and Bosworth turndown flap: a case report and literature review. Foot Ankle Surg 2012;18(3):e25-e28.

49. Cannon PS, Ajit R, Leatherbarrow B. Efficacy of trichloracetic acid (95\%) in the management of xanthelasma palpebrarum. Clin Exp Dermatol 2010;35(8):845-8.

50. Ghosh YK, Pradhan E, Ahluwalia HS. Excision of xanthelasmata clamp, shave, and suture. Int J Dermatol 2009;48(2):181-3. 